\title{
Estimulação ultra-sônica pulsada e contínua no processo cicatricial de ratos submetidos à celiotomia
}

\author{
Pulsed and continuous ultrasound stimulation in rats healing celiotomy
}

\author{
Débora Cristina Olsson $^{1}$ Vera Maria Villamil Martins ${ }^{1 *}$ \\ Edison Martins² Alexandre Mazzanti $^{3}$
}

\section{RESUMO}

Para avaliar a cicatrização de feridas cirúrgicas da parede abdominal de ratos submetidos à celiotomia, utilizou-se a terapia com ultra-som (US) nos modos contínuo e pulsado. Foram utilizadas 45 ratas, separadas em três grupos experimentais com 15 animais por grupo. A cicatrização da parede abdominal foi avaliada por esteriometria, sendo consideradas a proporção volumétrica dos constituintes tissulares e celulares de amostras de tecidos obtidos da parede abdominal às zero, 48, 96 e 144 horas após a celiotomia. Vinte e quatro horas após a intervenção cirúrgica, iniciou-se a aplicação de ultra-som (US) sobre a ferida. Os resultados obtidos com a aplicação de US no modo pulsado às 48 horas mostraram maior proporção volumétrica de células polimorfonucleares (PMN) e fibroblastos quando comparados com o grupo controle e com o grupo que recebeu aplicação de US no modo contínuo $(P \leq 0,05)$. Esses resultados mostram que a aplicação de US no modo pulsado auxilia na cicatrização de feridas cirúrgicas produzidas após celiotomia.

Palavras-chave: ultra-som, cicatrização, fisioterapia, rato.

\section{ABSTRACT}

In order to evaluate the healing process of surgical injuries on 45 rats submitted to celiotomy, ultrasonic continuous and pulsed energy was utilized. Forty-five female rats were used, separated in 3 experimental groups with 15 animals in each group. Healing was evaluated by stereometry, considering

\begin{abstract}
the volumetric proportion of the material in cellular and tissue samples, obtained from the abdominal wall biopsies at 0, 48, 96 and 144 hours after celiotomy. Ultrasound application on the surgical site was made 24 hours after the intervention. Results obtained with the application of ultrasound in the pulsed variety at 48 hours showed a larger volumetric proportion of polymorphonuclear cells and fibroblast when compared to the control group and to the group which received ultrasound application in the continuous variety $(P \leq 0.05)$. These results showed that the ultrasound application in the pulsed way can be recommended in the treatment of surgical wounds in the abdominal cavity.
\end{abstract}

Key words: ultrasound, healing, physiotherapy, mice.

\section{INTRODUÇÃO}

Os procedimentos cirúrgicos realizados no interior da cavidade celômica e nas áreas retroperitoniais têm como via de acesso a parede abdominal, considerando-se a celiotomia uma das práticas cirúrgicas mais freqüentes (FRY \& OSLER, 1991).

Em humanos, a deiscência, caracterizada pela separação dos planos profundos, ocorre entre zero e $6 \%$ das celiotomias, com taxas de mortalidade que

'Departamento de Clínica de Pequenos Animais, Programa de Pós-graduação em Medicina Veterinária, Laboratório de Cirurgia Experimental (LACE), Universidade Federal de Santa Maria (UFSM), Santa Maria, RS, Brasil.

${ }^{2}$ Departamento de Clínica e Patologia, Programa de Pós-graduação em Ciências Veterinárias, Hospital de Clínica Veterinária (HCV), Centro de Ciências Agroveterinárias, Universidade do Estado de Santa Catarina (CAV/UDESC). Rua Nereu Ramos, 73, apt ${ }^{\circ}$ 9b, 88502-090, Centro, Lages, SC, Brasil.

${ }^{3}$ Empresa de Pesquisa Agropecuária e Extensão Rural de Santa Catarina (EPAGRI), Programa de Pós-graduação em Ciências Veterinárias, HCV, CAV/UDESC, Lages, SC, Brasil.

${ }^{4}$ Departamento de Clínica de Pequenos Animais, Programa de Pós-graduação em Medicina Veterinária, Cirurgia Experimental,

LACE, UFSM, Santa Maria, RS, Brasil.

* Autor para correspondência. 
variam entre 9 e 44\% (SUTTON \& MORGAN, 1992). Na medicina veterinária, a celiotomia ventral na linha média é a via de acesso mais utilizada para abordagem cirúrgica em eqüinos com cólica (PAGLIOSA \& ALVES, 2004). Nesta espécie, as complicações incisionais podem chegar a 35\% (KOBLUCK et al., 1989).

Essas intercorrências retardam a cicatrização da ferida cirúrgica, aumentam o período de convalescença, e podem ser fatais (KOBLUCK et al., 1989; PAGLIOSA \& ALVES, 2004), além de aumentar os custos com o tratamento.

Para auxiliar na cicatrização das feridas cirúrgicas provenientes de celiotomias, busca-se recursos terapêuticos físicos que melhorem a qualidade e a velocidade de cicatrização. O ultra-som é uma modalidade de terapia física amplamente utilizada para tratar lesões em diversos tecidos (STARKEY, 2001; KORSTJENS et al., 2004). Este recurso aumenta o fluxo sangüíneo, a permeabilidade de membranas (STARKEY, 2001) e a ativação de fibroblastos, com aumento na produção de colágeno (KORSTJENS et al., 2004).

Muitos trabalhos realizados com terapia ultra-sônica mostraram resultados promissores; porém, ainda não há um consenso quanto ao tempo, dosimetria e modo de aplicação do ultra-som como auxiliar do processo cicatricial. Diante desses questionamentos, este estudo se propôs a avaliar os efeitos do ultra-som terapêutico nos modos contínuo e pulsado sobre a cicatrização de feridas produzidas durante a celiotomia em ratos.

\section{MATERIAL E MÉTODOS}

O experimento foi realizado no Núcleo de Fisiatria Veterinária do Hospital Veterinário (HCV) Lauro Ribas Zimmer do Centro de Ciências Agroveterinárias da Universidade do Estado de Santa Catarina (UDESC). Foram utilizadas 45 ratas da linhagem Wistar com três meses de idade e peso entre $250 \mathrm{e} 300 \mathrm{~g}$. Os ratos foram mantidos em gaiolas individuais, recebendo água e ração ad libitum por seis dias. Durante o experimento, foram cumpridas as exigências de conforto e bem-estar dos animais, de acordo com as normas do comitê de ética em experimentação animal (CETEA) da UDESC.

Os animais foram distribuídos aleatoriamente em três grupos experimentais, com 15 ratas por grupo, sendo que cada grupo correspondeu a um tratamento. No tratamento I, os animais não receberam ondas ultra-sônicas (testemunha); no tratamento II, os animais foram submetidos a aplicações de ultra-som ${ }^{d}$ no modo contínuo, na intensidade de $1 \mathrm{~W} \mathrm{~cm}{ }^{-2}$, freqüência de $1 \mathrm{MHz}$, durante cinco minutos, sobre a incisão cirúrgica. No tratamento III, os animais foram submetidos a aplicações de ultra-som no modo pulsado, na mesma intensidade, freqüência de $1 \mathrm{MHz}$ por cinco minutos, sobre a seç̧ão cirúrgica.

Cada grupo foi subdividido em três subgrupos de cinco animais, para avaliar, nos tempos de zero, 48, 96 e 144 horas após a intervenção cirúrgica, o efeito das aplicações ultra-sônicas.

No início do experimento, todos os animais foram submetidos à celiotomia mediana préretroumbilical. Para a intervenção cirúrgica, elas foram anestesiadas em aparelho de contenção com fluxo de halotano ${ }^{\mathrm{b}}$ e oxigênio de aproximadamente $2,0 \mathrm{~lm}^{-1}$, tricotomizadas na área cirúrgica e submetidos à celiotomia pré-retroumbilical.

Após anti-sepsia com álcool-iodado a 2\%, fez-se, com bisturi (lâmina 4), uma incisão penetrante de aproximadamente $4 \mathrm{~cm}$ na linha média ventral. De todos os ratos retirou-se um fragmento de $1 \mathrm{~cm}^{2}$ de cada lado da incisão cirúrgica, totalizando um fragmento de $2 \mathrm{~cm}^{2}$, contendo todos os tecidos da parede abdominal para avaliação histológica. Para mensurar os cortes, foi usado um molde plástico de $2 \mathrm{~cm}^{2}$; em seguida, suturou-se separadamente os tecidos da parede abdominal (músculo oblíquo abdominal externo, tecido subcutâneo e cutâneo) com fios mononáilon ${ }^{c}, 2-0$, através de pontos simples eqüidistantes.

Após o procedimento cirúrgico, todos os animais receberam analgésico (flunixim meglumine ${ }^{\mathrm{a}}$ ) em dose única de $2,5 \mathrm{mg} \mathrm{kg}^{-1}$ por via intramuscular. Vinte e quatro horas após a intervenção cirúrgica, iniciou-se a aplicação de ultra-som sobre a ferida, nos animais incluídos nos tratamentos II e III. Naqueles pertencentes ao tratamento I, realizou-se o mesmo procedimento, porém com o aparelho de ultra-som desligado.

No dia e hora zero do experimento, de 15 (tratamento I, II e III) dos 45 animais, foram retirados fragmentos de $2 \mathrm{~cm}^{2}$ da parede abdominal, mantendo a incisão centralmente a esses dois centímetros, para avaliações histomorfométricas dos constituintes celulares e tissulares. O mesmo procedimento foi realizado em cinco animais de cada tratamento às 48,96 e 144 horas após a cirurgia. Após as cirurgias e colheitas de fragmentos às 48,96 e 144 horas, a anestesia foi aprofundada até o óbito dos animais.

Os fragmentos de tecidos da parede abdominal (tecido cutâneo, subcutâneo, músculo oblíquo abdominal externo e peritônio) foram fixados em formalina tamponada a $10 \%, \mathrm{pH} 7,2$ por 24 horas e processados por técnicas rotineiras. Os cortes histológicos com espessura de $5 \mu \mathrm{m}$ foram distanciados entre si, no mínimo a cada $50 \mu \mathrm{m}$. De cada espécime colhido, confeccionou-se seis lâminas histológicas, 
sendo três coradas por Hematoxilina-Eosina e três por Tricômico de Gomori. As lâminas foram examinadas ao microscópio óptico nos aumentos de 100X, 200X e 400X.

Os cortes histológicos foram avaliados por esteriometria (DUBROVSKAIA, 1991; ERIKSEN et al., 1994) para determinar, em cada tratamento e tempo, a proporção volumétrica de fibroblastos, colágeno, angiogênese, células polimorfonucleares e mononucleares. Para a esteriometria, utilizou-se objetiva de 40 vezes e ocular de 10 vezes, dotada de retícula com 400 pontos eqüidistantes. O delineamento experimental foi inteiramente casualizado em fatorial (3 $\mathrm{X} 4$ ), que corresponde aos três tratamentos e aos quatro tempos (COCHRAN \& COX, 1957).

\section{RESULTADOS E DISCUSSÃO}

A quantidade da proporção volumétrica de células PMN no tratamento I aumentou até às 96 horas, sendo a proporção volumétrica maior às 96 horas do que às 48 horas, diminuindo sensivelmente às 144 horas (Figura la e 2a). No tratamento II, o comportamento foi similar ao tratamento I, porém a intensidade de células PMN às 96 horas não diferiu $(\mathrm{P}=0,05)$ daquela observada às 48 horas (Figura 2a).

No tratamento III, a maior quantidade de células PMN foi observada às 48 horas, diferindo dos tratamentos I e II. Segundo RANTANEN et al. (1999), cerca de seis horas após uma injúria, a margem da ferida contém fagócitos e, por volta das 24 horas, há um predomínio de células polimorfonucleares, diminuindo nas 48 horas seguintes, o que está de acordo com os resultados verificados no presente experimento, para o tratamento III. Estes resultados mostram que a aplicação do ultra-som no modo pulsado estimula mais precocemente a quimiotaxia para células PMN e conseqüentemente diminui o tempo do processo inflamatório

Na proporção volumétrica de células (Figura $1 \mathrm{~b}$ e $2 \mathrm{~b}$ ), o tratamento I (testemunha) demonstrou aumento às 48 horas, diminuindo às 96 horas $\mathrm{e}$ mantendo a mesma intensidade às 144 horas. No tratamento II (Figura 2b), não houve diferença na intensidade de células mononucleares nos tempos de 48, 96 e 144 horas; porém, houve aumento significativo quando comparada com os valores obtidos à zero hora (Figura 1b), o que significa que quanto maior for a duração do processo inflamatório, menor será a possibilidade de regeneração (ROMO III \& McLAUGHLIN, 2003). No tratamento III, a maior intensidade ocorreu às 48 horas, diminuindo progressivamente $(\mathrm{P} \leq 0,05)$ às 96 e 144 horas, respectivamente (Figura 2b). Esses achados também foram observados por RANTANEN et al. (1999), ao verificarem que, após 48 horas de evolução, o número de células PMN diminuiu sensivelmente, passando o exsudato a ser constituído predominantemente por macrófagos. No tratamento III, a intensidade de células mononucleares foi menor às 96 e 144 horas, do que aquelas observadas nos tratamentos I e II $(\mathrm{P} \leq 0,05)$ (Figura 2b). Isso caracteriza que, no tratamento III, o processo inflamatório foi de menor intensidade.

Na verificação da proporção volumétrica de fibroblastos (Figuras 1d e 2d), no tratamento I, a proporção volumétrica de fibroblastos nos tecidos adjacentes à incisão, às 48 horas, foi superior àquela observada no momento da intervenção cirúrgica $(\mathrm{P}=0,05)$, mantendo-se similar às 96 horas. Entretanto, às 144 horas, a proporção volumétrica foi maior em relação aos tempos anteriores $(\mathrm{P}=0,05)$ (Figura $1 \mathrm{~d}$ ). A aplicação do ultra-som no modo contínuo (tratamento II), determinou um aumento progressivo da proporção volumétrica de fibroblastos das zero às 144 horas, em que os quatro tempos analisados diferiram entre si $(\mathrm{P}=0,05)$. No tratamento III, houve um aumento na proporção volumétrica entre às zero, 48 e 96 horas, porém, às 144 horas, a proporção não diferiu daquela observada às 96 horas (Figura 2d). O tratamento com ondas ultra-sônicas pulsadas interferiu positivamente no processo de reparo quanto à proliferação de fibroblastos na rápida remodelagem da ferida cirúrgica.

Os tratamentos I e II foram semelhantes quanto à proporção volumétrica de fibroblastos às 48 e 96 horas, com menor aumento desse índice no tratamento II, às 144 horas. No entanto, no tratamento III, às 48 horas, a proporção volumétrica foi maior quando comparada aos tratamentos I e II $(\mathrm{P}=0,05)$. No tratamento III, a proporção volumétrica de fibroblastos apresentou um comportamento diferente dos demais tratamentos, com maior proporção volumétrica de fibroblastos, já a partir das 48 horas, mantendo-se até às 144 horas (Figura 1d).

Segundo a publicação de ROMO III \& McLAUGHLIN (2003), os fibroblastos começam a migrar para as margens da ferida em torno das 48 horas, quando aumentam em número, tornam-se ativados, com início da síntese dos componentes da matriz extracelular.

A rápida capacidade cicatricial foi verificada pela expressiva ativação da fibroplasia, que está presente na fase de proliferação celular, e que é extremamente importante na formação do tecido de granulação, incluindo fibroblastos, células inflamatórias e componentes neovasculares. Estas características foram verificadas de forma precoce no presente experimento, quando da aplicação de ultra- 
som pulsado. O uso desse tipo de energia também é descrito por YOUNG \& DYSON (1990) em lesões de pele, sobre as quais observaram aumento na quantidade de fibroblastos, do tecido de granulação e diminuição de leucócitos no grupo tratado, em relação ao grupo controle.

A intensidade de $1 \mathrm{~W} \mathrm{~cm} \mathrm{~cm}^{-2}$, freqüência de $1 \mathrm{MHz}$ e tempo de cinco minutos utilizados neste experimento produziram efeitos tissulares positivos, não sendo observados danos celulares. Segundo FERNANDES et al. (2003) e BYL et al. (1992), dependendo da intensidade, tempo e freqüência das aplicações, podem haver danos teciduais, retardando a cicatrização.

Resultados positivos sobre a cicatrização de feridas produzidas em suínos também foram verificados por BYL et al. (1992), ao utilizarem a freqüência de $1 \mathrm{MHz}$, intensidade de $0,5 \mathrm{~W} \mathrm{~cm} \mathrm{~cm}^{-2}$ por três dias. Os autores observaram aumento significativo na força de contração e taxa de cicatrização do grupo tratado.

A fase de fibroplasia também caracteriza-se pela presença de colágeno, sendo composto principalmente de glicina, prolina e hidroxiprolina, sendo que, para sua formação, requer enzimas específicas que exigem co-fatores como oxigênio e ácido ascórbico, daí suas deficiências levaram ao retardo da cicatrização. De acordo com BYL et al. (1993), o aumento da fibroplasia com a aplicação de ultra-som pulsado na freqüência de $1 \mathrm{MHz}$, intensidade de $1,5 \mathrm{~W}$ $\mathrm{cm}^{-2}$, evidencia aumento nos níveis de fibroblastos, hidroxiprolina e colágeno, quando utilizado uma intensidade ultra-sônica menor.

A intensidade da proporção volumétrica de angiogênese foi semelhante entre os três tratamentos e verificou-se aumento significativo $(\mathrm{P}=0,05)$ da neovascularização às 48 horas, mantendo-se às $96 \mathrm{e}$ 144 horas (Figura 1c). No tratamento III, às 144 horas, a angiogênese foi menor do que nos tratamentos I e II, e menor do que às 96 horas, o que poderia estar relacionado com a precocidade de resolução do processo cicatricial, uma vez que a resposta inflamatória foi de menor duração neste tratamento (figuras 1c e 2c).

Estes achados estão de acordo com o estudo desenvolvido por SHWEIKI et al. (1992), ao verificarem que, na privação de oxigênio, as células liberam fatores angiogênicos e ocorre a formação de novos capilares, porém com a diminuição do processo inflamatório, esses capilares regridem ou desaparecem. Segundo os mesmos autores, a neoangiogênese é essencial para o processo de reparação, porque pode garantir um abundante suporte de $\mathrm{O}_{2}$ para a área lesada e a remoção do $\mathrm{CO}_{2}$ e outros metabólitos. A presença de oxigênio também é fundamental para a hidroxilação dos aminoácidos lisina e prolina e para a formação do colágeno e sua maturação. Verificou-se que, nos três tratamentos, a intensidade da angiogênese foi semelhante nos tempos 48, 96 e 144 horas (Figura 2c), com um aumento significativo em relação ao tempo zero.

Estes resultados diferem daqueles observados por KOECKE (2003), ao trabalhar com reparo de tendões, e FERNANDES et al. (2003), ao estudarem os efeitos de ultra-som na regeneração muscular, os quais concluíram que, na avaliação histológica, a neovascularização foi pronunciada. Provavelmente essa observação se deva à dosimetria, às estruturas anatômicas e ao tempo de irradiação, uma vez que pequenas variações na freqüência, potência, tempo e forma de aplicação podem gerar resultados diferentes (FERNANDES, et al., 2003; BYL et al., 1992), devido a complexa interação do ultra-som com os tecidos.

A proporção volumétrica de colágeno (Figuras 1e e 2e) nos três tratamentos foi similar às zero, 96 e 144 horas, sendo que, no tratamento I e tratamento no II, as proporções volumétricas de colágeno às 48 horas foram inferiores às encontradas no tratamento III (Figura 1e). No tratamento I, ocorreu aumento de colágeno às 96 horas após a incisão cirúrgica. No tratamento II, a proporção volumétrica de colágeno foi similar às 48 horas e às 96 horas, apresentando maiores índices que aqueles observados às zero e 144 horas. No tratamento III, a maior intensidade de colágeno foi observada às 48 horas, sendo significativamente superior àquela encontrada às zero, 96 e 144 horas (Figura 2c). Dentre os tratamentos e os tempos, a maior proporção volumétrica de colágeno ocorreu no tratamento III, às 48 horas, diferindo dos demais tratamentos neste mesmo tempo. Às zero e 144 horas, não houve diferença entre os tratamentos. Confrontando os resultados obtidos para fibroblastos e para colágeno, observou-se que a maior fibroplasia ocorreu até às 96 horas, com a aplicação de ultra-som no modo pulsado (tratamento III), e que a maior produção de colágeno foi observada no mesmo tratamento, às 48 horas.

Embora fosse esperado que a maior proporção volumétrica de colágeno (tratamento III) às 48 horas estivesse associada à maior fibroplasia (tratamento III, às 96 horas), deve-se levar em consideração as observações de RODLAND et al. (1990), ao verificarem que a ativação dos fibroblastos se faz por diversos fatores, incluindo o fator de crescimento derivado das plaquetas (PDGF), que expõe 


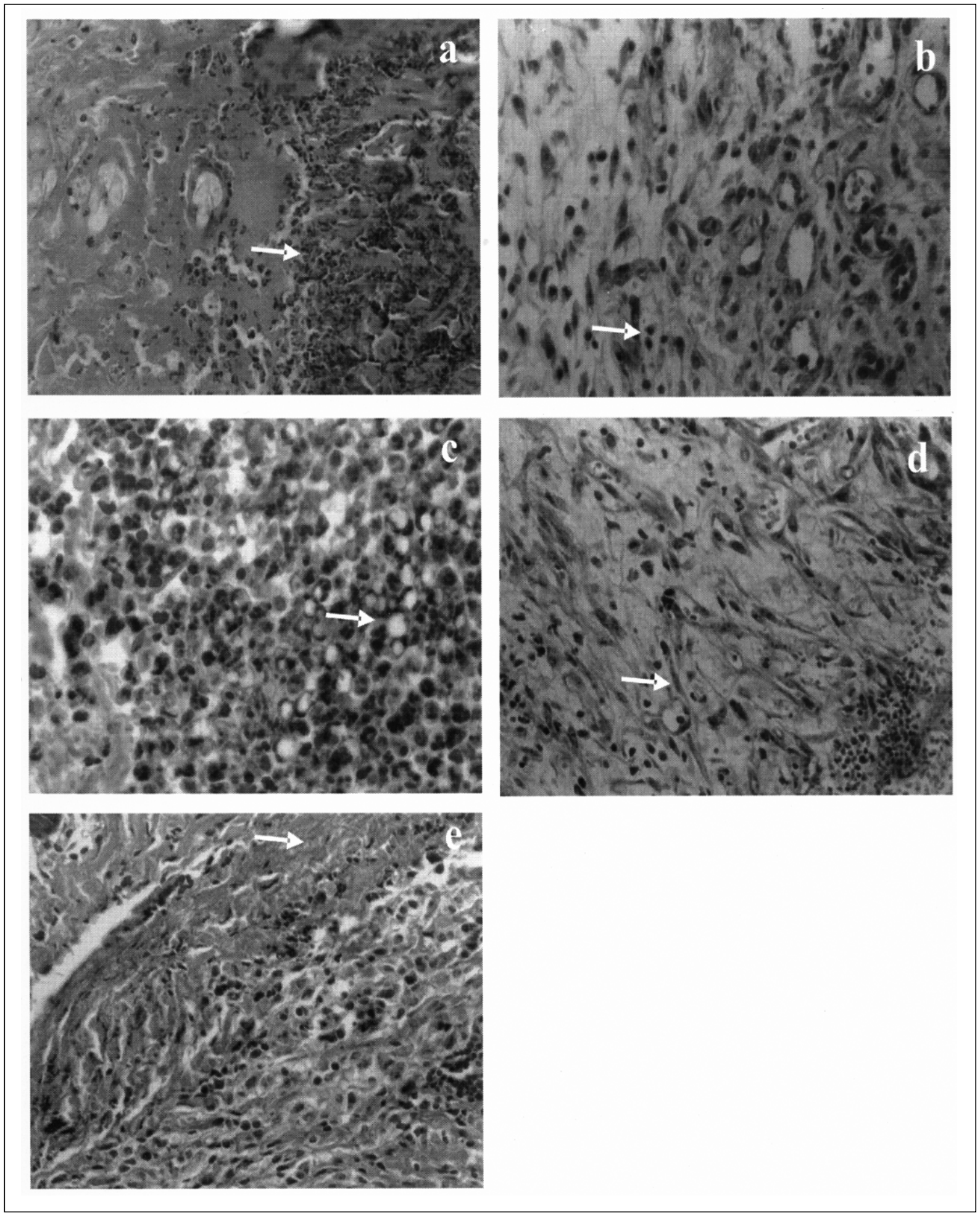

Figura 1 - Fotomicrografia de processo cicatricial de celiotomia em ratos submetidos à terapia ultra-sônica pulsada e contínua. a) tratamento I, às 144 horas, presença de grande quantidade de células polimorfonucleares (seta): b) tratamento II, às 96 horas, grande quantidade de células mononucleares (seta); c) tratamento II, às 96 horas, intensa neovascularização (seta); d) tratamento III, às 144 horas, presença de grande quantidade de fibroblastos (seta); e) tratamento III, às 48 horas, grande quantidade de colágeno (seta). 320X. 


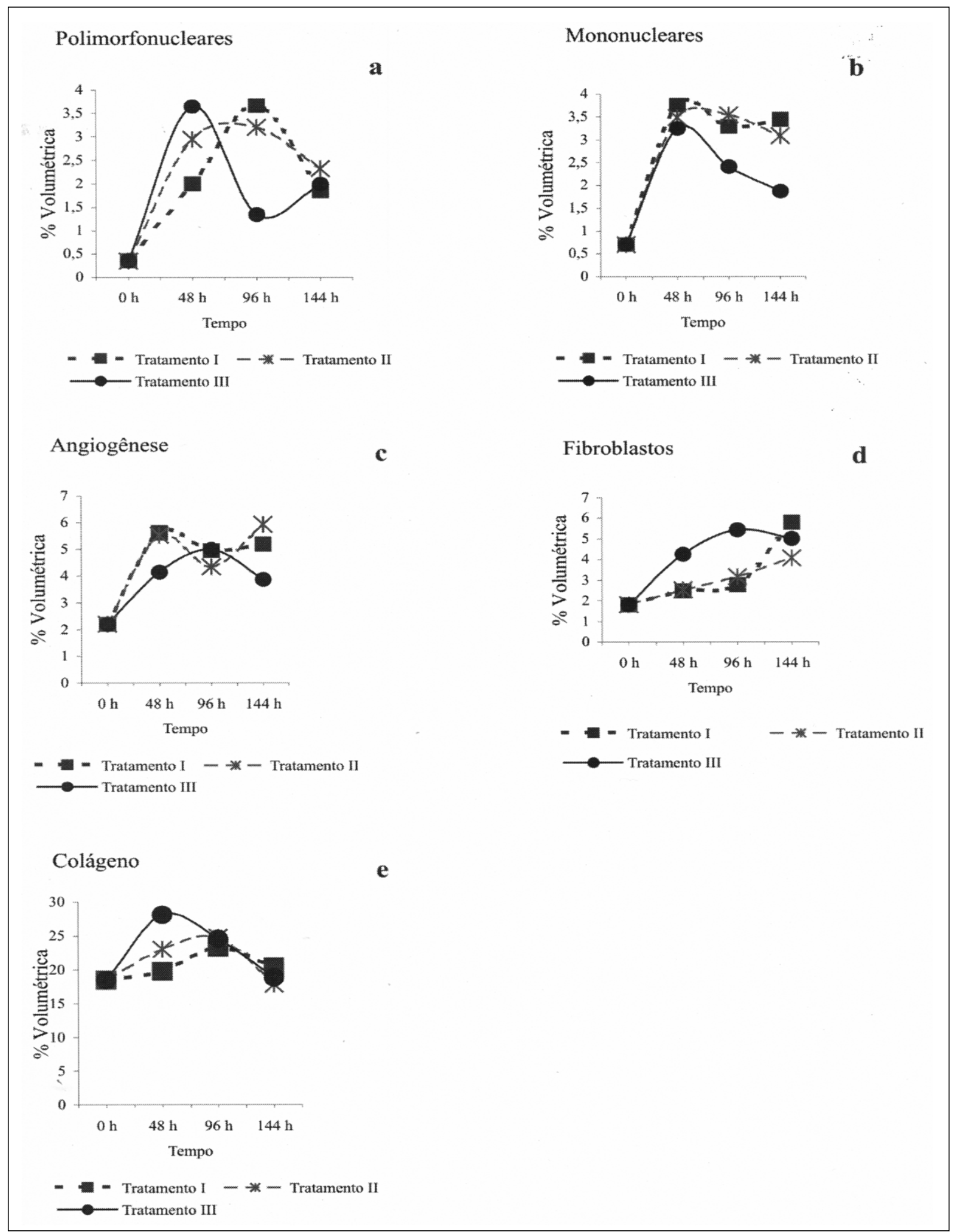

Figura 2 - Proporção volumétrica de células PMN (a); células mononucleares (b); angiogênese (c); fibroblastos (d) e colágeno (e), nos tratamentos I, II e III, nos tempos zero, 48, 96 e 144 horas.

Ciência Rural, v.36, n.3, mai-jun, 2006. 
receptores para outros fatores de crescimento. Entre esses, inclui-se o fator básico de crescimento para fibroblastos (FGFb), produzido pelos próprios fibroblastos e pelas células endoteliais com ação mitogênica e também pela indução da síntese dos componentes da matriz extracelular.

No entanto, segundo FALANGA et al. (1988), o FGFb tanto pode estimular quanto inibir os fibroblastos, tornando-se importante no mecanismo de retroalimentação da síntese e degradação do colágeno, bem como na própria cicatrização da ferida. A interleucina 1 (IL-1), fator de crescimento de necrose tumoral alfa (TNF-a) e fator de necrose tumoral (TNF) produzidos por macrófagos também são estimuladores potentes da síntese de colágeno pelos fibroblastos, embora não tenham efeito mitogênico sobre essas células (ROMO \& McLAUGHLIN, 2003).

\section{CONCLUSÕES}

Os resultados obtidos nas condições em que foi realizado o experimento permitem concluir que em feridas cirúrgicas produzidas na parede abdominal, a aplicação do ultra-som no modo pulsado, com doses na freqüência de $1 \mathrm{MHz}$ e intensidade de $1 \mathrm{~W} \mathrm{~cm}^{-2}$ reduz o tempo da reação inflamatória e acelera a cicatrização, favorecendo precocemente a reparação tecidual, sendo seus efeitos superiores aos do modo contínuo.

\section{AGRADECIMENTOS}

Ao programa de Pós-graduação em Ciências Veterinárias-PPGCV, do Centro Agroveterinário da Universidade do Estado de Santa Catarina (CAV/UDESC - SC). À Coordenação de Aperfeiçoamento de Pessoal de Nível Superior (CAPES), pela concessão de bolsa de estudo para realização deste curso. À EPAGRI (Estação Experimental de Lages, SC.), por ter permitido a utilização do laboratório para a realização da morfometria.

\section{APROVAÇÃO DO BEM ESTAR ANIMAL}

O presente experimento foi aprovado pelo Comitê de Ética e Experimentação Animal (CETEA) do Centro de Ciências Agroveterinárias da Universidade do Estado de Santa Catarina (CAV/UDESC), de acordo com legislação vigente e os Princípios Éticos publicados pelo COBEA (Colégio Brasileiro de Experimentação Animal).

\section{FONTES DE AQUISIÇÃO}

a)Banamine (flunixim meglumine) - Schering-Plough; b)Halotano - Cristália Prod. Quim. Farm. LTDA; c) Mononálion - Ehticon d)Ultra-som terapêutico - modelo Sonacel Plus (ERA 3,5 $\mathrm{cm}^{2}$ ).

\section{REFERÊNCIAS}

BYL, N.N. et al. Low-dose ultrasound effects on wound healing: A controlled study with Yucan pigs. Arch Phys Med Rehabil, v.73, p.656-664, 1992.

BYL, N.N. et al. Incisional wound healing: a controled study of low and high dose ultrasound. J Orth Sp Phys Ther, v.18, n.5, p.619-628, 1993

COCHRAN, W.G.; COX,G.M. Experimental designs. New York: Wiley, 1957. 611p.

DUBROVSKAIA, V.F. Dynamics of structural parameters of mast cells and accumulation of collagen fibers during radiationinduced pneumosclerosis in rats (a quantitative study). Radiobiologia. v.31, p.485-490, 1991.

ERIKSEN, E.F. et al. Bone histomorphometry. New York: Haven, 1994. 120p.

FALANGA, V. et al. Wound healing. J Am Acad Dermatol, n. 19, p.559-563, 1988 .

FERNANDES, M.A.L. et al. Efeito do ultra-som terapêutico em tendinite experimental de eqüinos: estudo clínico, ultrasonográfico e histopatológico de dois protocolos. Arq Bras Med Vet Zootec, v.55, n.1, p.27-34, 2003.

FRY, D.E.; OSLER, T. Considerações sobre a parede abdominal e complicações na cirurgia reoperatória. Clin Cir Am Norte, n.71, p.1-11, 1991 .

GUIRRO, R.; SANTOS, S.C.B. A realidade da potência acústica emitida pelos equipamentos de ultra-som terapêutico: uma revisão. Rev Fisioter Univ São Paulo, v.4, n.2, p.76-82, 1997.

KOBLUK, C.N. et al. Factors affecting incisional complication rates associated with colic surgery in horses: 78 cases (19831985). J Am Vet Med Assoc, v.195, n.5, p.639-642, 1989.

KOEKE, P.U. Estudo comparativo da eficácia da fonoforese, do ultra-som terapêutico e da aplicação tópica de hidrocortisona no tratamento do tendão de rato em processo de reparo tecidual. 2003. 164f. Dissertação (Mestrado em Bioengenharia) - Escola de Engenharia de São Carlos/Faculdade de Medicina de Ribeirão Preto/Instituto de Química de São Carlos, Universidade de São Paulo.

KORSTJENS, C.M. et al. Stimulation of bone cell differentiation by low-intensity ultrasound: a histomorphometric in vitro study. J Orthop Res, v.22, n.3, p.495-500, 2004.

LOW, J.; REED, A. Ultra-som terapêutico. In: Eletroterapia aplicada: princípios e prática. São Paulo: Manole, 2001. Cap.6, p.187-228.

PAGLIOSA, G.M.; ALVES, G.E.S. Fatores predisponentes das complicações incisionais de laparotomias medianas em eqüinos. Ciência Rural, v.34, n.5, p.1655-1659, 2004.

RANTANEN, J. et al. Effects of therapeutic ultrasound on the regeneration of skeletal myofibres after experimental muscle injury. Amer J Sports Med, v.27, n.1, p.54-59, 1999. 
RODLAND, K.D. et al. Cellular mechanisms of TGF- $\beta$ action. J Invest Dermatol, v.94, p.27-33, 1990.

ROMO III, T.; McLAUGHLIN, L.A. Wound healing, skin 2003. Acesso em: 10 out. 2004. On line. Disponível em: $<$ www.emedicine.com/ent/topic13.htm>.

SHWEIKI, D. et al. Vascular endothelial growth factor induced by hypoxia may mediate hypoxia - initiated angiogenis. Nature, n.359, p.843-845, 1992.
STARKEY, C. Recursos terapêuticos em fisioterapia. 2.ed. São Paulo: Manole, 2001. 404p.

SUTTON, G.; MORGAN, S. Abdominal wound closure using a running looped monofilament polybutester suture: comparasion to Smead-Jones closure in historic controls. Obstet Gynecol, n.80, p.650-654, 1992.

YOUNG, S.R.; DYSON, M. Effect of therapeutic ultrasound on the breaking of fullthickness excise skin lesions. Ultrasonic, v.28, n.3, p.175-180, 1990. 